\title{
LEVANTAMENTO ARQUEOLÓGICO NO NOROESTE DO PARANÁ, ENTRE A FOZ DOS RIOS PARANAPANEMA E IVAÍ*
}

\author{
Francisco Silva Noelli ** \\ Marcos Rafael Nanni *** \\ Lúcio Tadeu Mota ** \\ Margarida Cardozo Lavado ** \\ Eurides Roque de Oliveira ** \\ Carlos Panek Jr** \\ Ana Paula Simão ** \\ Fernando Jerônimo ** \\ Washington Castilho ** \\ João Batista da Silva $* * * *$
}

Desde 1996 o Laboratório de Arqueologia, Etnologia e Etno-História (LAEE) - Programa Interdisciplinar de Estudos de Populações, da Universidade Estadual de Maringá (UEM), desenvolve pesquisas no noroeste do Paraná visando conhecer a região para instalar um programa permanente de Arqueologia Pública e Regional. Em 2000 iniciamos o levantamento arqueológico sistemático nos municípios de Diamante do Norte, Marilena, Nova Londrina, Porto Rico, São Pedro do Paraná, Querência do Norte e Santa Cruz do Monte Castelo (Fig. 1), por ocasião dos estudos preliminares para a formação da Área de Proteção Ambiental Federal do Noroeste do Paraná (APA). As evidências obtidas contribuem com dados favoráveis para as hipóteses sobre a ocupação Guarani na região (Brochado 1984; Noelli 1996, 2000a, 2000b), demonstrando que a área pesquisada foi ocupada de forma contínua e densa por essas populações.

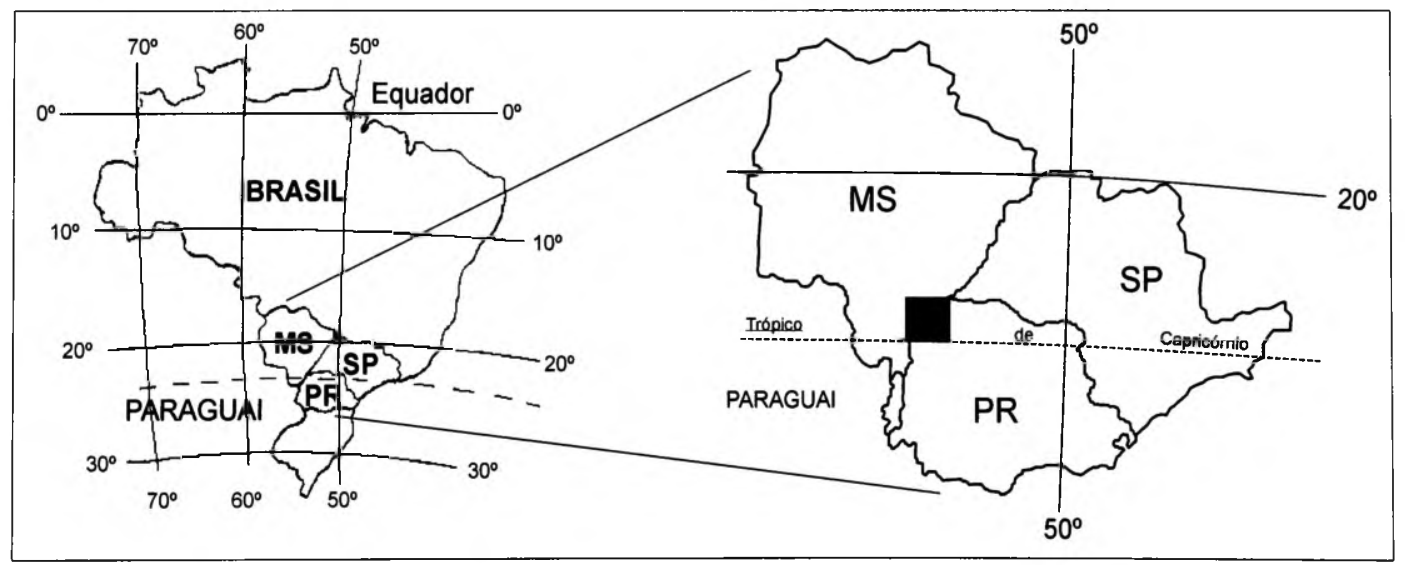

(*) Este trabalho é uma versão ampliada e corrigida do texto publicado nos anais do $8^{\circ}$ Encontro Regional de História da ANPUH-PR, realizado em Curitiba em 2002. O projeto foi financiado pelo Consórcio Municipal da APA Federal do Noroeste do Paraná, em convênio com a Universidade Estadual de Maringá (Processo 524-00/ Zoneamento Ecológico/Econômico da APA Federal das ilhas e das várzeas do rio Paraná).

(**) Laboratório de Arqueologia, Etnologia e EtnoHistória - Universidade Estadual de Maringá.

(***) Departamento de Agronomia - Universidade Estadual de Maringá.

(****) Museu da Bacia do Paraná. 


\section{Resultados preliminares da pesquisa arqueológica}

A pesquisa de reconhecimento da paisagem e levantamento arqueológico de evidências superficiais foi dividida em duas etapas. A primeira foi o levantamento no trecho à beira-rio, visando atender aos objetivos da formação da APA. A segunda etapa cobrirá as áreas municipais do interior, onde serão examinadas as microbacias e áreas potenciais para a instalação dos assentamentos mais afastados do rio Paraná, considerando o relevo, abastecimento de água, tipos de solos e outros elementos da natureza (a meta é percorrer a maior parte da superfície dos sete municípios). Foi coberta a pé e de forma sistemática, na beira dos rios Paranapanema, Paraná e Ivaí, uma faixa de $120 \mathrm{~km}$ de comprimento por 3 $\mathrm{km}$ de largura, entre a represa de Rosana, em Diamante do Norte e a foz do rio Ivaí, em Querência do Norte, bem como boa parte do litoral do rio Ivaí no município de Santa Cruz do Monte Castelo (Fig. 2). Localizamos 68 ocorrências arqueológicas de superfície (OAS), totalizando um número mínimo de 29 e um máximo de 33 sítios arqueológicos, caso algumas OAS sejam mais de um sítio (Tabela 2). A Figura 2 mostra a área de pesquisa e a localização das OAS. Também consideramos e incluímos os registros de outros pesquisadores que estiveram na área, nas décadas de 60 e 80, somando 9 sítios (Blasi 1961; Chmyz 1974, 1991, 1992).

Não realizamos nenhum tipo de escavação ou coleta de superfície, limitando-nos apenas ao mapeamento e registro das OAS e análise preliminar das evidências in situ. Essa metodologia não permitiu, nesta fase inicial da pesquisa, definir se algumas OAS correspondiam a um ou mais sítios arqueológicos, mas decidimos registrá-las, em razão da proximidade espacial que sugere conexão entre elas, com apenas um sítio. Ainda temos poucas informações sobre o tamanho real dos sítios arqueológicos, mas alguns revelaram dimensões maiores que $1,5 \mathrm{~km}$ de comprimento, como o PR $\mathrm{PP}-06$, que está parcialmente soterrado/destruído pelo núcleo urbano de Porto Rico (Fig. 2). Os demais dependem da continuidade das pesquisas para terem suas dimensões efetivamente definidas. A maioria das OAS apresenta evidências cerâmicas típicas Guarani (Brochado 1984; La Salvia e Brochado 1989), e a maioria dos sítios líticos sugerem, por sua situação estratigráfica, vinculação direta com os sítios Guarani. A situação das evidências possui um padrão similar aos registros arqueológicos Guarani localizados no Paraná (Chmyz 1992), Mato Grosso do Sul (Kashimoto 1998) e São Paulo (Faccio 1998), apresentando concentrações de fragmentos cerâmicos e líticos de superfície com dimensões variando entre $25 \mathrm{e}$ $1.000 \mathrm{~m}^{2}$. A maioria das OAS possui forma elipsoidal, com o eixo maior geralmente disposto em paralelo ao leito do Paraná e do Paranapanema.

Os estudos quaternários realizados por geólogos do Grupo de Estudos Multidisciplinares do Ambiente (GEMA) e do Departamento de Geografia, ambos da UEM, indicam que o início da ocupação Guarani coincide com as mudanças climáticas e fitogeográficas ocorridas no noroeste paranaense. Os Guarani estariam entrando na região ao redor de 200 a.C., perto do final de um período de aridez ocorrido entre 3.500 a.C. e 500 d.C. (Jabur 1992; Stevaux e Santos 1998; Noelli 2000b). A aridez contribuiu para a formação de áreas de cerrado, com predomínio de campos e capões com espécies arbustivas e com a retração das áreas florestais. Posteriormente, o aumento gradativo da umidade a partir de 500 a.C. causou uma gradativa mudança na fisionomia vegetal, contribuindo para aumentar as áreas de floresta e tornando o ambiente favorável à ocupação Guarani, que instalava suas aldeias e roças no interior da floresta. Essas alterações ambientais estão marcadas na estratigrafia da região, permitindo uma interpretação preliminar sobre o processo de ocupação humana e a definição de um método preditivo para diferenciar os sítios Guarani dos pré-ceramistas. Em princípio, como pudemos observar em diversos pontos da Região Noroeste do Paraná, entre os dois tipos de sítios encontra-se uma camada de sedimentos eólicos estéreis depositados no período de aridez, permitindo considerar os sítios líticos superficiais como áreas de atividade Guarani e não como sítios préceramistas, uma vez que a maioria das OAS líticas estão nas mesmas camadas que as OAS cerâmicas. No futuro testaremos se essa seqüência estratigráfica é constante ou se alguns sítios líticos superficiais são pré-cerâmicos. Consideramos, com base na observação da estratigrafia da área em questão, assim como de trechos do médio rio Ivaí, do rio Paraná no trecho cidade de Guaíra-foz do Ivaí, e do médio Pirapó, que é provável que a maioria dos sítios pré-cerâmicos está abaixo da camada de sedimentos eólicos estéreis, em média abaixo dos $50-60 \mathrm{~cm}$ a partir da superfície atual. 


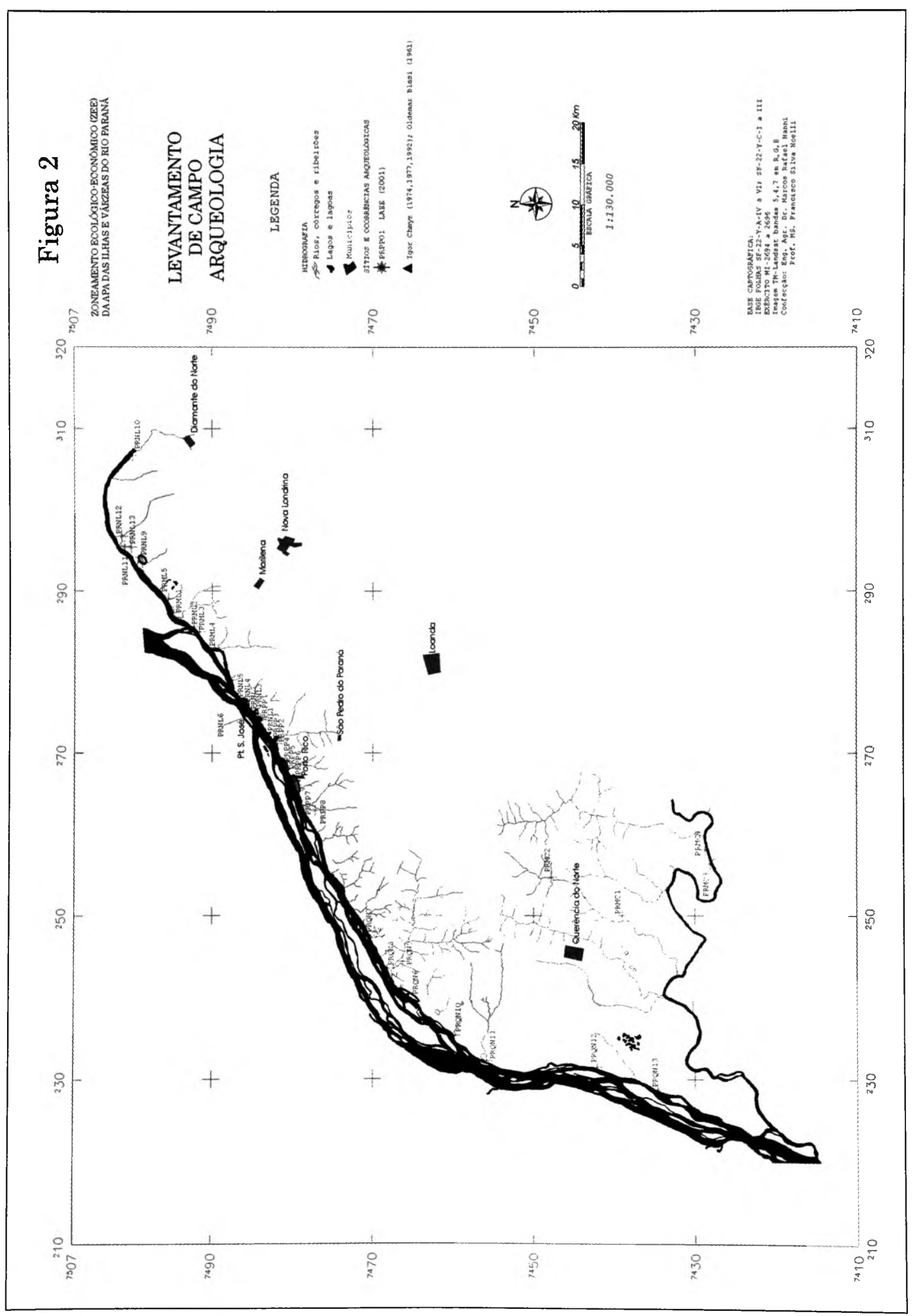




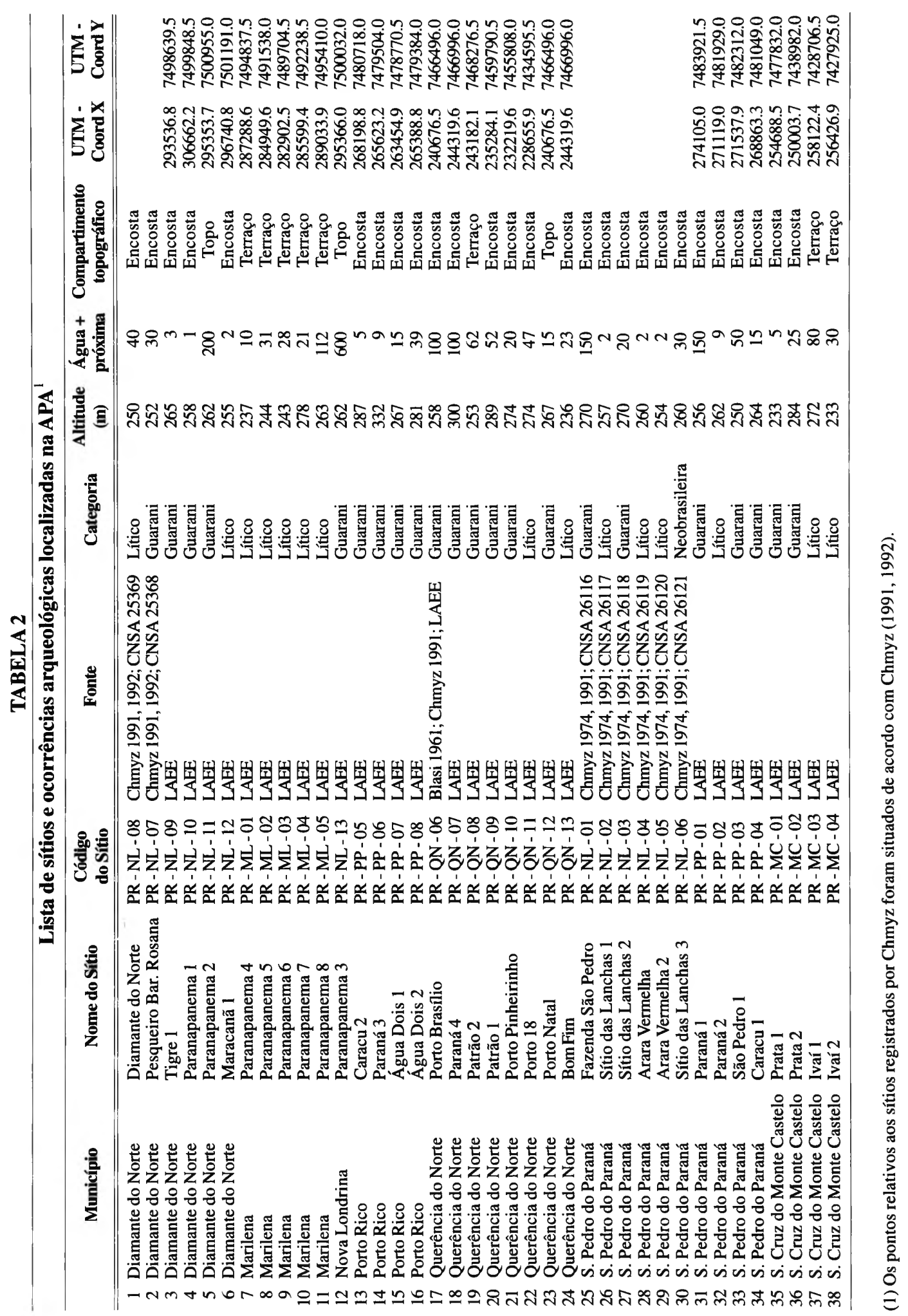




\section{Conclusão}

Encerramos a primeira etapa de um projeto de longa duração, concluindo a fase do reconhecimento arqueológico inicial da APA Federal do Noroeste do Paraná. Na próxima etapa começaremos a refinar nossas informações com o aprofundamento das pesquisas de campo sítio-a-sítio, por meio de estudos estratigráficos e contextuais de cada unidade, visando definir como eram as aldeias, quando e como os Guarani ocuparam a região. Também iremos pesquisar com os mesmos objetivos os assentamentos pré-ceramistas. Esperamos encontrar no registro arqueológico uma série de evidências que revelem aspectos bioantropológicos dos seus ocupantes e sobre sua vida social e econômica. Nas fontes escritas procuraremos elementos que nos ajudem a compreender aspectos estruturais de organização social e política Guarani no período final da ocupação, bem como diversos outros temas de interesse arqueológico. Por fim, o conjunto dos registros da APA, somados aos sítios localizados nas partes vizinhas do Mato Grosso do Sul e São Paulo, mostram claramente que esta área é de grande interesse arqueológico e possui grande potencial de pesquisa, que precisa ser realizada $e$ desenvolvida junto com um plano de manejo $e$ proteção dos sítios que atraia o interesse da população local, tanto para o conhecimento do passado, quanto para a preservação do seu patrimônio arqueológico.

\section{Agradecimentos}

Aos professores da UEM, Issa C. Jabur; Sérgio L. Thomaz e José C. Stevaux. A responsabilidade pelo conteúdo, evidentemente, restringe-se exclusivamente aos autores dessa publicação.

\section{Referências bibliográficas}

BLASI, O.

1961 Algumas notas sobre a jazida arqueológica de 3 Morrinhos - Querência do Norte - Rio Paraná. Boletim Paranaense de Geografia, 2 (3): 49-78.

CHMYZ, I.

1974 Dados arqueológicos do baixo rio Paranapanema e do alto rio Paraná. PRONAPA 5. Publicações avulsas do Museu Paraense Emílio Goeldi, 26: 67-90.

CHMYZ, I

1991 Relatórios do Projeto Arqueológico Ilha Grande. Curitiba/Campo Grande: Etrosul/ FUFPR/FUFMS

\section{CHMYZ, I.}

1992 Relatório de atividades do Projeto Arqueológico Rosana-Taquaruçu. Curitiba: Convênio CESP/FUNPAR,

FACCIO, N.

1998 Arqueologia do cenário das ocupações horticultoras da Capivara, Baixo Paranapanema - SP. São Paulo, Tese de Doutorado, Faculdade de Filosofia, Letras e Ciências Humanas, Universidade de São Paulo.

JABUR, I.C.

1992 Análise paleoambiental do Quaternário Superior na bacia hidrográfica do alto rio
Paraná. Rio Claro, Tese de Doutorado, Universidade do Estado de São Paulo.

\section{KASHIMOTO, E.M.}

1997 Variáveis ambientais e arqueológicas no alto Paraná. São Paulo, Tese de Doutorado, Faculdade de Filosofia, Letras e Ciências Humanas, Universidade de São Paulo.

1996 As hipóteses sobre o centro de origem e as rotas de expansão dos Tupi. Revista de Antropologia, 39 (2): 7-53.

NOELLI, F.S.

2000a A presença Guarani desde 2.000 anos atrás: contribuição para a História da ocupação humana do Paraná. R.C. Rolim, S.A. Pellegrini, R.B. Dias (Orgs.). História, espaço e meio ambiente (VI Encontro Regional de História, ANPUH - PR). Maringá: ANPUH: 403-414.

2000 b A ocupação humana na região sul do Brasil: Arqueologia, debates e perspectivas - 1872 2000. Revista USP, 44: 218-269.

\section{STEVAUX, J.C.; SANTOS, M.L}

1998 Palaeohydrological changes in the upper Paraná river, Brazil, during the late Quaternary: a facies approach. G. Benito; V.R. Baker; K.J. Gregory (Eds.) Palaeohydrology and environmental change. New York: Willey: 273-285. 